\title{
DIREITO NATURAL E CODIFICAÇÃO: ATUALIDADE DO MÉTODO REALISTA CLÁSSICO DE TEIXEIRA DE FREITAS
}

\author{
Alfredo de J. Flores
}

\section{INTRODUÇÃO}

Eis uma questão que poucas vezes teve uma apreciação mais profunda por parte dos juristas e teóricos do Direito - a relação entre os princípios e o método do Direito Natural e o modelo contemporâneo de legislação, a codificação. Nesse sentido, o primeiro passo para compreender tal relação, ao menos dentro do Direito brasileiro, seria buscar o fundamento de tal compreensão na experiência jurídica nacional. Nesse caso, é inegável a relevância da figura de Augusto Teixeira de Freitas $^{1}$, um

* Doutor em Direito e Filosofia pela Universitat de València (Espanha). Professor Adjunto de Metodologia Jurídica (UFRGS). Docente Permanente do Programa de Pós-Graduação em Direito (PPGDir, UFRGS). Sócio do Instituto de Filosofia e Ciência do Direito - 'Lex et Ius' (Porto Alegre). Socio aderente da Asociación Argentina de Filosofía del Derecho (AAFD).

1 Augusto Teixeira de Freitas nasceu em 19 de agosto de 1816 na vila de Cachoeira, atualmente no estado da Bahia, no Brasil. Os seus estudos jurídicos foram feitos na Academia de Olinda, onde iniciou no ano de 1832, terminando em 1837, depois de passar uma época no Largo de São Francisco, em São Paulo, durante o período de 1833 a 1835. Em 1844, no Rio de Janeiro, na época, capital do Império brasileiro, foi nomeado para auxiliar o Conselho de Estado, fazendo pareceres para o governo. Em 1855 foi encarregado de fazer uma compilação de leis civis do país, finalizada em 1857 como a Consolidação das leis civis; posteriormente, fez o primeiro projeto de Código civil do Brasil, no período 1859-1865, que ficou conhecido como o Esboço do Código civil. Publicou livros e advogou até a sua morte, ocorrida em 1883 em Niterói, no atual estado do Rio de Janeiro. Outras informações sobre o grande jurista brasileiro são encontradas nas biografias de Manoel Sá Vianna (VIANNA, Manoel A. de S. Sá. Augusto 
autor que pertenceu a uma outra época dentro da história do Direito brasileiro, em que a legislação nacional era incipiente e a ciência era quase que inexistente na área jurídica, mas que com sua aguda percepção da realidade dos fenômenos jurídicos, em especial nas relações de Direito privado, estabeleceu uma sólida base para o Direito nacional.

Quanto a isso, vale lembrar inicialmente que o citado autor foi o famoso codificador brasileiro que haveria de produzir o mais significativo projeto de Código Civil na América Latina, o Esboço do Código Civil. A partir desta e de outras obras, o seu pensamento chegaria a influenciar de modo sensível o trabalho de vários juristas, diríamos em todos os âmbitos, desde os legisladores nacionais e estrangeiros, e nisso se pode fazer menção a Vélez Sarsfield, o codificador argentino que fez seu projeto a partir do modelo formal do Esboço, projeto esse que depois seria a legislação vigente naquele país, até os advogados da prática forense brasileira do Império e do início da República.

Mas não somente por isso; é necessário asseverar que a relevância desse pensador brasileiro não se reduz a um mero enquadramento como um operador do Direito de êxito no século XIX. É preciso ainda recordar que o seu projeto de Código Civil apresentava um molde tipicamente moderno, dentro do debate daquele momento sobre a codificação, mas também considerava toda a tradição do Direito anterior, seja no que tange ao aspecto material, da legislação nacional vigente e portuguesa, que era a sua base, seja no que se refere ao aspecto formal, das instituições jurídicas, em que o Direito romano era o fundamento e exemplo.

Tais elementos justificam o enfoque utilizado neste exame, em que se toma o ponto de vista da história da ciência jurídica brasileira para demonstrar que o trabalho de Teixeira de Freitas representa uma nova concepção dentro do pensamento jurídico no século XIX. Fala-se de uma nova concepção porque há desdobramentos do debate europeu, o qual se centrou no eixo exegético-pandectista, a ponto de aperfeiçoá-lo mediante o diálogo entre a técnica rigorosa de codificação do autor brasileiro e os valores e métodos da antiga tradição jurídica que remonta ao fundo jurídico lusobrasileiro.

Em vista disso, a análise que será feita neste trabalho se desdobrará em três partes, a saber: (1) a importância

Teixeira de Freitas: traços biográficos. Rio de Janeiro: Typographia Hildebrandt, 1905) e de Sílvio Meira (MEIRA, Sílvio. Teixeira de Freitas: o jurisconsulto do Império. $2^{\mathrm{a}}$ ed. Brasília: Cegraf, 1983). 
de Teixeira de Freitas, (2) seu contexto histórico e, finalmente, (3) a percepção da presença do Realismo filosófico no pensamento desse jurista, o que mostra a singularidade da história da ciência jurídica no Brasil em razão desse autor.

\section{A IMPORTÂNCIA DE TEIXEIRA DE FREITAS}

A abordagem inicial se vincula à figura de Teixeira de Freitas, no sentido de buscar perceber a sua contribuição para a compreensão do pensamento jurídico do século XIX. Nesse caso, pode-se apreciar, nessa primeira análise sobre o tema, o valor dos trabalhos do jurista ao menos em dois pontos de vista, os quais podem mostrar o peso específico de seu ideário no cenário nacional, que são: (1.1) o aspecto científico-jurídico de sua obra e (1.2) os possíveis questionamentos filosóficos a partir de seu pensamento.

\section{$1.1 \mathrm{O}$ aspecto científico-jurídico de sua obra}

$\mathrm{O}$ que se deve ressaltar numa primeira abordagem é a valia específica que possuiria a obra de Teixeira de Freitas dentro do contexto jurídico latino-americano. Com efeito, há uma vasta doutrina entre os atuais romanistas que assevera que Teixeira de Freitas é o responsável por construir uma unidade no Direito latinoamericano, segundo se pode constatar nos escritos dos professores italianos Sandro Schipani ${ }^{2}$ e Pierangelo Catalano ${ }^{3}$.

De fato, a respeito disso, pode-se asseverar que a imagem de Teixeira

2 Uma explicação sobre a importância do "sistema latino-americano" pode ser vista em seu artículo: SCHIPANI, Sandro. Sistemas jurídicos e Direito romano. As codificações do Direito e a unidade do sistema jurídico latino-americano. In: LANDIM, José Paes (Org.). Direito e integração. Brasília: UnB, 1981, p. 34-53, esp. p. 40 e 47.

3 Já na opinião de Pierangelo Catalano (segundo o seu livro Diritto e persone. Studi su origine e attualità del sistema romano. vol. I. Torino: Giappichelli, 1990, p. 195-215, esp. p. 195), é possível falar que, na época contemporânea, existem duas linhas no pensamento jurídico: a linha justinianeia, que continua na área de influência ibérica e que seria a base do "sistema latino-americano" com A. Teixeira de Freitas, e a linha pandectista europeia, que definiu a ciência jurídica ocidental. Ante tal separação, aponta de uma forma categórica esse autor que, apesar de alguma abstração nos conceitos do citado “sistema latino-americano”, a verdade é que tal sistema está conectado à concreta realidade do homem, especialmente quando se constata entre as linhas do Esboço do Código Civil o reconhecimento da existência dos seres humanos concebidos no ventre materno, as “pessoas por nascer”, dando seguimento à tradição jurídica romano-ibérica dentro de um contexto moderno. 
de Freitas se conforma a tal visão, por vários motivos. Assim, em seus escritos, repassa a obra de Andrés Bello, o ilustre venezuelano que haveria de redigir o Código Civil chileno em meados do século XIX, como também, segundo se disse antes, influiria na obra de Vélez. A julgar por tal relevância de sua obra na história da codificação latino-americana, pode-se indicar que foi o responsável pela unidade da dogmática jurídica civil na América do Sul, o que já foi dito por alguns autores. Contudo, vale lembrar que tal uniformidade se manifestaria numa teoria geral do Direito comum, conforme se percebe na técnica codificatória da época. Em outros termos e partindo propriamente da perspectiva da ciência jurídica, existem elementos que mostram um critério para construir uma técnica jurídica mais adequada ao contexto cultural da América Latina, os quais já se apresentavam nos livros do jurisconsulto brasileiro 4 .

Essa imagem, que é retratada por tais romanistas italianos, reconhece uma faceta particular da obra de Teixeira de Freitas, a sua influência na construção da dogmática jurídica. Além disso, seria o sinal para que fosse possível vislumbrar claramente qual foi o papel que teve esse jurista na teoria jurídica nacional. Nesse sentido, essa afirmação tem um respaldo nos grandes autores brasileiros, como se pode depreender até mesmo do singular F. C. Pontes de Miranda, quando este chega a afirmar em seu Tratado de Direito privado que é discípulo das ideias de Teixeira de Freitas 5 , tido como o grande jurista brasileiro do Império.

4 É um exemplo claro dessa influência de Teixeira de Freitas o sistema civil construído pelo jurista argentino Vélez Sarsfield. Com efeito, S. Meira consegue explicitar isso ao fazer um paralelo entre os projetos desses dois autores, comparando-os no que tange a vários artigos, e também com relação à sistemática que haveria de ser adotada em ambos os trabalhos legislativos. Efetivamente, a citada comparação de Sílvio Meira pode ser observada mais detalhadamente em seu artigo "Direito brasileiro e Direito argentino (Códigos comercial e civil) - influência do 'Esboço' de Teixeira de Freitas no Projecto de Vélez Sarsfield". In: AAVV. Estudos jurídicos em homenagem ao Professor Caio Mário da Silva Pereira. Rio de Janeiro: Forense, 1984, p. 345-390, esp. p. 371-378.

5 O vínculo com o ideário de Teixeira de Freitas foi declarado pelo próprio Pontes de Miranda, quando chega a afirmar que "há certo fio de coerência histórica e espiritual em realizarmos, já no plano da sistematização, com o material do direito vigente, complexo e de diferentes datas, versado lealmente, o que, no plano da técnica legislativa, fora o sonho do jurista brasileiro, há quase um século", em seu renomado livro Tratado de Direito privado. (Tomo I. Rio de Janeiro: Borsoi, 1954, p. XXIII). 


\subsection{Os possíveis questionamentos filosóficos a partir de seu pensamento}

Por outro lado, podem-se cogitar algumas questões de ordem filosófica a respeito da visão que Teixeira de Freitas tinha sobre a técnica jurídica. Assim, a existência de pelo menos três aspectos deveriam ser ressaltados.

Em primeiro lugar, a necessidade da leitura filosófica dos fenômenos jurídicos. Aqui se nota que não se pode reduzir a realidade a uma hipótese teórica e, em particular, quando se observa a interpretação histórica de um prático de prestígio como Teixeira de Freitas. Em tal caso, os vários trabalhos desse jurista manifestam uma concepção do jurídico que abarca todos os âmbitos. Assim, quando se dedica à codificação civil, deixa ver uma concepção teórico-filosófica que serve de base ao empreendimento técnico. Além disso, vale ressaltar que a sua visão de técnica jurídica tem a pretensão de apresentar-se como modelo de uma verdadeira construção técnica no Direito. É assim que se manifesta a primeira questão filosófica ${ }^{6}$ baseada nas ideias de Teixeira de Freitas presentes em suas obras: em que medida a técnica construída por esse mesmo jurista nos seus modelos de sistematização da matéria civil corresponde a uma ordenação racional por excelência dessa mesma matéria.

Nesse caso, pode-se afirmar que o essencial é referir que a técnica codificatória é uma espécie de técnica jurídica vinculada à necessidade de elaborar a legislação; em outros termos, não se refere prima facie a um juízo particular de aplicação da legislação aos casos concretos, pois se encontra no âmbito do universal. Esse âmbito da generalidade da regra legislativa determina a característica primeira da obra codificatória, o que Teixeira de Freitas de fato veio a perceber, de modo especial quando

6 Por isso, Teixeira de Freitas aludia a uma sistematização racional afirmando que "a divisão é instrumento da analyse; mas, terminada esta, e conhecidas as differenças e semelhanças dos entes ou factos observados; a classificação, instrumento da synthese, os distribue, não em series isoladas, mas em classes superiores e inferiores, subordinadas umas às outras, e formando um verdadeiro systema, que não é um simples arranjamento e superposição, mas um tecido, um aggregado de partes reciprocamente unidas", conforme se percebe no seu livro crítico do projeto de Código português (TEIXEIRA DE FREITAS, Augusto. Nova apostilla à censura do Senhor Alberto de Moraes Carvalho sobre o Projecto do Codigo civil portuguez. Rio de Janeiro: Typographia Universal de Laemmert, 1859. p. 52). 
buscava a excelência ${ }^{7}$ no ato da construção do sistema legislativo civil. Consequentemente, tendo a oportunidade de aperfeiçoar um tipo de técnica jurídica por intermédio de seu trabalho codificatório, Teixeira de Freitas consegue perceber que a constituição da técnica, ainda que se trate da elaboração de textos legais, deve sempre acompanhar a realidade dos fenômenos, mas com vistas à universalidade que lhe é própria.

Em segundo lugar e também como uma consequência deste primeiro postulado, é possível fazer alusão ao rigor lógico demonstrado pelo jurista

na elaboração do projeto de Código, pois definiu as regras segundo a natureza de cada instituição jurídica, ordenando todas as instituições civis dentro de um sistema jurídico ${ }^{8}$, o Esboço, que justamente haveria de influenciar vários codificadores latino-americanos.

A perfeição que buscava na elaboração do sistema jurídico civil, segundo se nota no projeto de Código que elaborou, resultou da apurada técnica jurídica ${ }^{9}$ que dominava. Isso explica a razão de Teixeira de Freitas conseguir alcançar a excelência nessa técnica a ponto de respaldar

7 Alguns autores chegam a falar de perfeccionismo, como H. Guimarães, que deu uma forte ênfase no que se refere à importância dessa característica na personalidade de Teixeira de Freitas (GUIMARÃES, Hahnemann. Teixeira de Freitas - sua vida e sua obra. Revista Forense, fev. 1944, vol. 97, p. 253-255, esp. p. 255), apontando como algo positivo no método de trabalho do civilista brasileiro. Já N. Sampaio afirmava que era um "vir bonus, iuris peritus" (homem bom, perito em Direito), pois havia encarnado em sua própria vida as virtudes públicas e privadas (bondade, honra e abnegação) típicas dos juristas romanos, o que explica como o autor nutria uma admiração pela civilização romana (SAMPAIO, Nelson. Teixeira de Freitas - sua vida e sua obra. Revista Forense, fev 1944, vol. 97, p. 257-263, esp. p. 259).

8 Desde a Consolidação, preocupava-se Teixeira de Freitas com um critério de ordenação, "para achar, porém, os limites do Direito Civil, e a norma da exposição das materias que lhe pertencem, recorremos á estudos de outra natureza, consultámos os monumentos legislativos, revimos e meditamos as tradicções da sciencia, e com toda a liberdade de espirito procuramos essa unidade superior que concentra verdades isoladas, penetra as mais reconditas relações, e dá esperanças de um trabalho consciencioso" (Consolidação das leis civis. $2^{\mathrm{a}}$ ed. Rio de Janeiro: Typographia Universal de Laemmert, 1865, p. VII).

9 Em razão disso, Teixeira de Freitas buscava entender a essência da realidade jurídica; por essa razão, o autor asseveraria que procurava "examinar as leis em seus proprios textos sem influencia de alheias opiniões, comparar attentamente as leis novas com as antigas, medir com precisão o alcance e consequencias de umas e outras, eis o laborioso processo, que empregado temos para conhecer a substancia viva da Legislação" (TEIXEIRA DE FREITAS, Augusto. Consolidação das leis civis. $2^{\mathrm{a}}$ ed. cit., p. VII). 
os fenômenos mediante a construção de elementos linguísticos e técnicos em prol da busca da harmonia nas relações humanas.

Por fim, o terceiro aspecto é que toda a construção jurídica tinha por fundamento a realidade das relações jurídicas, no sentido defendido por Savigny $^{10}$ em momento anterior a Teixeira de Freitas. Nessa perspectiva, essa postura estava presente no pensamento do jurista brasileiro com a peculiaridade de uma interpretação desde a tradição jurídica clássica. Apesar disso, é preciso lembrar que Teixeira de Freitas sempre buscou tratar o fenômeno jurídico baseado em uma linguagem moderna ${ }^{11}$, de modo particular quando enfrentou as dificuldades próprias de construir um conjunto de conceitos e regras no processo de codificação civil.

Partindo desses aspectos propostos, fica claro que o trabalho de elaboração do Esboço do Código Civil, sob a responsabilidade de Teixeira de Freitas, mostra-se como uma tarefa tipicamente jurídica, em que se percebe um profundo respeito para com a natureza das relações e instituições jurídicas. Dessa forma, é possível notar que a tarefa codificatória contemplou até mesmo os detalhes da fenomenologia jurídica, pois o sistema de regras foi elaborado em conformidade com a técnica jurídica. Disso se conclui que Teixeira de Freitas é um notável exemplo de

10 Quanto à importância da relação jurídica, realçava Savigny, “das Rechtsverhältniß aber hat eine organische Natur, und diese offenbart sich theils in dem Zusammenhang seiner sich gegenseitig tragenden und bedingenden Bestandtheile, theils in der fortschreitenden Entwicklung, die wir in demselben wahrnehmen, in der Art seines Entstehens und Vergehens" (VON SAVIGNY, F. C. System des heutigen Römischen Rechts. Band 1. Berlin: Veit und Comp., 1840, p. 7-8).

11 Dentro da visão moderna, Teixeira de Freitas defende o papel dos direitos subjetivos na ordenação jurídica, "aqui não ha classificação alguma, não ha qualquer systema, ou baseado no ponto de vista do sujeito activo do direito, ou derivado da observação dos direitos, que são protegidos e regulados pela Legislação Civil propriamente dita. Em qualquer desses dous aspectos, para que houvesse um systema, para que houvesse um plano natural e logico; fôra de mister, que se tivesse dividido a massa dessa synthese confusa, - o sujeito activo do direito, ou os direitos (faculdades); que se a tivesse observado, estudado, e analysado, em cada uma de suas partes; - que, analysadas e bem conhecidas todas as partes, se as comparasse entre si, para que surgissem suas differenças e semelhanças; - que, discriminadas as differenças, se fizessem classes primarias, e subordinadas; - e que por fim apparecêssem essas classes em um só corpo, ligadas umas ás outras, formando um tecido, um aggregado de partes reciprocamente unidas" (Nova apostilla á censura do Senhor Alberto de Moraes Carvalho sobre o projecto de Codigo civil portuguez. cit., p. 56-57). 
codificador que define uma ideia de construção de sistema civil em que predomina o conhecimento jurídico de caráter prático, o que determina a natureza da técnica legislativa pelo necessário vínculo com a realidade das relações jurídicas.

Partindo dessa linha de raciocínio, pode-se apontar que existem algumas inferências que podem ser feitas desde o questionamento filosófico que foi proposto com base na obra de Teixeira de Freitas e que podem servir de corolário destas considerações sobre o papel do autor.

Inicialmente, e desde um ponto de vista mais genérico, é possível notar em Teixeira de Freitas a presença do ideário do Realismo filosófico clássico em sua conotação aristotélico-tomista, desde uma perspectiva de diálogo constante com a experiência jurídica moderna, a qual por sua vez é permeada pela experiência da construção da codificação e da interpretação jurídica. Efetivamente, o pensamento aristotélico se conforma na tradicional ${ }^{12}$ compreensão jurídica tributária ao Direito romano e que manifesta uma visão das instituições e relações do Direito. Tal noção se consolidou no discurso jusnaturalista que é defendido pelo autor, dentro de um padrão de leitura que se insere numa visão de mundo cristã e que entende que existem elementos de verdade científica dentro das manifestações das regras e instituições jurídicas na história.

12 Explica C. Massini a visão realista do Direito desde o caráter prático do fenômeno jurídico, como legatário do pensamento aristotélico e do romano, "creo que nadie podrá negar sensatamente que el derecho es algo que el hombre hace en vistas a su bien propio, específicamente, a su bien propio en la vida común. Pertenece, por lo tanto, al orden práctico y debe consistir, desde esta perspectiva, en un determinado obrar del hombre; ello en razón de que el ser humano edifica su vida - y por consiguiente su vida perfecta - a través de un obrar personal, de una serie de actos concretos dirigidos hacia la obtención de los bienes que el hombre necesita para su vida y, sobre todo, para su vida perfecta. En este caso, dada la radical politicidad del derecho, para el bien común o vida perfecta común en la sociedad política y por su intermedio para el bien personal de cada uno de los integrantes del todo social. Es por lo antedicho que la 'realidad justa' de que habla Santo Tomás para referirse al derecho esencialmente, siguiendo en esto a la tradición aristotélica y romana, viene a ser una 'obra justa', una actividad social del hombre ordenada al bien común a través de los títulos jurídicos de otro. El mismo Santo Tomás se refiere numerosas veces al derecho como 'obra adecuada a otro' o como 'acto' humano rectificado por la justicia. Por otra parte, es lógico que así sea, toda vez que si el orden práctico [...] se halla encaminado a la perfección del hombre, perfección que se logra a través de un cierto obrar, el derecho - parte integrante de ese orden - no puede consistir esencialmente sino en una cierta obra, en un determinado obrar del hombre, ordenado en este caso al bien humano común”, no seu livro sobre o tema - MASSINI, Carlos. Sobre el realismo jurídico. Buenos Aires, Abeledo-Perrot, 1978, p. 17-18. 
Além disso, com essa concretização por parte de Teixeira de Freitas da visão realista no processo codificatório brasileiro, fica provada a aplicabilidade ${ }^{13}$ das noções filosóficas clássicas na construção de um sistema jurídico propriamente moderno, o Código. Esse fato normalmente não é ressaltado nas atuais pesquisas sobre a história do pensamento jurídico, em especial porque alguns autores jusnaturalistas entendem que a visão jurídica clássica somente poderia ser abarcada pela concreção judicial. De fato, com tal postura se favorece a tentativa de reduzir e enquadrar as atividades jurídicas somente a um campo, o âmbito concreto que é dominado pela razão prática (a "dianoia praktike" aristotélica). Claro está que a razão prática é a base do Direito; porém, não é a totalidade da experiência do
Direito, pois assim deixaria em aberto o problema da codificação.

A existência da realidade técnica demanda a utilização da razão produtiva ou técnica (a que Aristóteles chama de "dianoia poietike"). $\mathrm{E}$ a isso se acrescenta a razão teórica (que é chamada de "dianoia theoretike") que estuda o universal. De qualquer maneira, é possível notar a fidelidade de Teixeira de Freitas aos princípios jusnaturalistas com base no caráter peculiar do pensamento jurídico lusobrasileiro de sua época, com uma abertura ao método sistemático pelo Iluminismo católico que era professado desde a reforma do Marquês de Pombal em Portugal, desde meados até fins do século XVIII, em que se percebe a defesa no discurso governamental dos valores cristãos ${ }^{14}$ e o apego à tradição jurídica lusitana.

13 Isso explica porque Teixeira de Freitas chega a anotar que "nós tambem por largo tempo, em todo o decurso de nossa pratica forense, muito pensamos sobre este assumpto, compulsamos os monumentos legislativos, combinamos com elles todas as theorias conhecidas, fechamos os livros, e interrogamos a natureza das cousas" (TEIXEIRA DE FREITAS, Augusto. Nova apostilla á censura do Senhor Alberto de Moraes Carvalho sobre o Projecto do Codigo civil portuguez. Cit., p. 10).

14 Nesse sentido, importa recordar o que haveria de explicitar corretamente A. F. Pereira, "queremos dizer que a sua congênita disposição prática, que o leva a erigir a vida humana, concebida como livre, em critério supremo da legislação, encontra confirmação no direito romano, generalizando-se filosoficamente na ideia de natureza das coisas, natura rerum. Com efeito, a noção de natureza das coisas, a que frequente e sistematicamente recorre Teixeira de Freitas, como decisiva ultima ratio no seu discurso jurídico, não é senão a palavra-chave, a fórmula condensada da teoria greco-romana, aristotélica, do direito natural”, em seu elucidativo artigo "O uso brasileiro do Direito romano no século XIX. Papel de Teixeira de Freitas”. In: SCHIPANI, Sandro (Org.). Augusto Teixeira de Freitas e il Diritto latinoamericano. Padova: Cedam, 1988, p. 8399, esp. p. 95. 
Por outro lado, isso ocorreu mediante a necessidade de adequar a legislação aos ventos daquela época, de caráter iluminista, e ao tema de momento, a reforma do Estado e da sociedade.

\section{$2 \mathrm{O}$ contexto histórico do autor}

O fato de que Teixeira de Freitas viesse a defender pontos de vista da noção clássica do Direito durante o século XIX merece explicações mais detalhadas, especialmente no que tange a poder indicar as causas da adoção de tal visão por parte do jurisconsulto brasileiro. É relevante anotar que sua visão técnico-jurídica se coaduna com sua concepção de ciência do Direito, e ao examinar-se o fundo filosófico de seu discurso, é notório que Teixeira de Freitas apresenta particularidades distintas de grande parte dos juristas de sua época. Entre tais particularidades, é possível indicar algumas, como o valor do Direito romano ${ }^{15}$ como causa exemplar do estudo das instituições jurídicas, bem como a tradição do Realismo jurídico clássico e a análise da realidade desde as relações jurídicas.

Contudo, isso demanda outra questão muito relevante: qual é a ex- plicação para o fato de que Teixeira de Freitas se orientasse para a concepção clássica, quando os ventos de sua época indicavam para outra direção. A resposta para essa questão se encontra na compreensão que teve o jurista brasileiro de sua experiência na área do Direito. Por essa razão, é necessário resgatar os elementos presentes em seu contexto histórico, com os quais se pode entender a via tomada por Teixeira de Freitas em relação a seu tempo. Tais elementos são visualizáveis a partir de três enfoques distintos: (2.1) a tradição jurídica luso-brasileira, (2.2) o pensamento jurídico anterior a Teixeira de Freitas e (2.3) o ideário dos juristas da época do autor.

\subsection{A tradição jurídica luso- brasileira}

O primeiro indício dessa compreensão de Teixeira de Freitas foi a própria tradição jurídica presente no Brasil a partir do período em que se deu a colonização por Portugal. Com isso, pode-se dizer que o Direito lusitano da época se apresentava como o fundamento da experiência jurídica brasileira incipiente. No caso mais

15 Realçando o papel do Direito romano no pensamento do grande jurista brasileiro, explicaria J. C. Moreira Alves que, no conjunto da obra de Teixeira de Freitas, revela-se uma "preocupação por extrair do Direito romano seu conteúdo jurídico, para, submetendo-o a exame crítico, aferir-lhe a validade na disciplina das necessidades sociais de seu tempo", como se nota em seu texto. MOREIRA ALVES, José Carlos. A formação romanística de Teixeira de Freitas e seu espírito inovador. In: SCHIPANI, Sandro (Org.). Augusto Teixeira de Freitas e il Diritto latinoamericano. Cit., p. 17-39, esp. p. 21. 
próximo de nosso autor, pode-se afirmar que, antes da reforma implementada por Pombal (particularmente com os trabalhos de 1769 a 1772), predominou a concepção jurídica que foi chamada correntemente na doutrina como "bartolismo", que, por sua vez, seria a técnica de interpretação e aplicação do Direito que remonta à noção medieval lusitana do Direito comum $^{16}$. Trata-se aqui da atualização da visão do "ius commune" medieval para o contexto da Idade Moderna, com as mudanças que com o tempo os vários autores foram estabelecendo para o uso do Direito romano, bem como para o método utilizado, que apresentou as suas variações.

De outra banda, essa tradição jurídica foi revitalizada a partir da consolidação, desde a Península ibérica, da doutrina escolástica tardia. Nesse aspecto, a revisão e atualização do pensamento tomista no início da Modernidade vai resultar no movimento da Segunda Escolástica, que teve também seu braço português por influência do ramo mais famoso, o da Espanha. Dentro do contexto do descobrimento da América e da transformação social, política e religiosa da Europa de então, o trabalho dessa Escola, atendendo a tais mudanças, representou a formação de uma nova concepção do Direito comum em seus fundamentos, com base em debates filosófico-jurídicos em torno das obras de Vitoria e Suárez. Isso ocorre em consonância com a tradição jurídica anterior, mas em atenção ao novo contexto, em que o tema é o "Direito das Gentes”. De qualquer forma, a prática jurídica lusitana coadunava a utilização das Ordenações reais com o uso do Direito subsidiário, especialmente o texto justinianeu e os comentários de Acúrsio e Bártolo.

\subsection{O período anterior ao jurista}

A reforma pombalina buscava representar uma transformação radical no Estado e na sociedade portuguesa de então. Contudo, resultou na consolidação de um modelo da

16 O "bartolismo" é uma característica do Direito brasileiro, de raiz lusitana, como anota J. H. Martins-Costa, “a expressão 'bartolismo', [...], indica o fato de as sentenças judiciais refletirem as opiniões de autores de diversos sistemas jurídicos, servindo-se os juízes de autores nacionais e de outros países, 'como se existisse ainda um 'Direito Comum' supranacional'. Esta é uma especificidade própria do sistema jurídico brasileiro e que justifica a maior abertura que as nossas sentenças têm para a doutrina, 'que é, assim, fonte de direito". O bartolismo, assim considerado, advém de um específico fenômeno, resultante da lacunosidade das Ordenações e das regras de sobredireito ali consignadas' (MARTINS-COSTA, Judith H. A boa-fé no Direito privado: sistema e tópica no processo obrigacional. São Paulo: Edit. Revista dos Tribunais, 1999, p. 241). 
prática jurídica que dialogava com a visão tradicional anterior, ainda que se apresentasse como tributário ao "Praxismo" alemão (também conhecido como "Usus modernus Pandectarum”, de autores como H. Conring e J. Heineccius). No caso português, surgem com o tempo os grandes autores de finais do século XVIII e início do século XIX, como Mello Freire, Lobão e Borges Carneiro, que, por sua vez, influenciam diretamente ${ }^{17}$ os juristas brasileiros com base nessa nova mentalidade.

Essa influência na prática jurídica provinha, na verdade, de um fundamento teórico que permeava os trabalhos legislativos elaborados sob o comando do Marquês de Pombal. Nesse sentido, é desde o discurso oficial de Pombal que se pode perceber a consolidação da nova doutrina jurídica em Portugal, de raiz jusracionalista, sendo conjugada com o enfoque "praxista" que estava em voga no período, particularmente no eixo centro-europeu. Importa ressaltar que é particularmente na Península ibérica que se percebe tal passagem do modelo antigo (ainda vinculado ao "mos italicus" tardo-medieval) à visão moderna "praxista", sem sofrer maiores reflexos dos polêmicos debates que eram próprios do humanismo do norte da Europa.

De qualquer forma, vale lembrar que a conjugação feita por Pombal se fundava nos estudos empreendidos a partir de 1746 na obra ${ }^{18} O$ verdadeiro método de estudar de L. A. Verney, autor esse vinculado ao pensamento de L. Muratori, um renomado autor italiano da época. Com a obra de Verney, Pombal aproveita para concretizar nos trabalhos legislativos as ideias que o próprio Marquês havia tomado conhecimento quando de sua estadia como diplomata português em Viena. Durante o período em que comandou o país, Pombal busca firmar os ali-

17 Na opinião de C. do Couto e Silva, "os juristas brasileiros anteriores à independência do Brasil eram todos praxistas, preocupados com a aplicação no foro dos princípios das Ordenações e suas leis complementares ou extravagantes”. DO COUTO E SILVA, Clóvis Veríssimo. O direito civil brasileiro em perspectiva histórica e visão de futuro. In: DE FRADERA, Véra J. (Org.). O direito privado brasileiro na visão de Clóvis do Couto e Silva. Porto Alegre: Livraria do Advogado, 1997, p. 12.

18 O texto de Luis AntonioVerney saiu com o pseudônimo de "Frei Barbadinho da Congregação da Itália”, pois o autor vivia em Roma. O título original foi o seguinte: Verdadeiro método de estudar, para ser util à Republica, e à Igreja: proporcionado ao estilo, e necessidade de Portugal. Valencia: Oficina de Antonio Balle, 1746. 
cerces de sua política legislativa, de modo especial ${ }^{19}$ mediante trabalhos como o Compêndio histórico do Estado da Universidade de Coimbra de 1771 e os Estatutos da Universidade de Coimbra de 1772.

\subsection{O pensamento jurídico da época do jurisconsulto}

Pode-se dizer que, na época de Teixeira de Freitas, em especial durante a produção de suas obras, o que compreenderia os anos de 1857 a 1883, houve o predomínio no Brasil de uma mentalidade jurídica ecléti$\mathrm{ca}^{20}$. Na verdade, já se sentia isso no plano filosófico a partir do ecletismo espiritualista que era tributário ao ilustre pensador francês Victor Cousin e que, até 1870, dominava o cenário nacional com nomes como Monte Alverne, o Visconde do Uruguai e até mesmo o imperador D. Pedro II. Ademais, em termos políticos, a concepção eclética se justificava no contexto de construção de uma identidade nacional, o que repercutiu na política legislativa, como se pode observar nas incumbências de Teixeira de Freitas

19 Afirma R. M. C. Gauer a respeito disso que "com a clara influência de Pufendorf e Thomasen, o direito natural passou a ser visto como um produto da razão e não da revelação divina ou vontade humana constituída em poder. Os compendiaristas utilizaram de tal forma o direito natural com base em Pufendorf, Wolff, Heineck, Bohemer, Darjes, Barbeirac e Thomasen, que esses autores são citados continuamente no 'Compêndio Histórico'; [...] Martini influenciou os compendiaristas na elaboração do 'Compêndio Histórico' e dos ‘Estatutos'”, como se pode observar na sua obra sobre o tema. GAUER, Ruth Maria Chittó. A construção do Estado-Nação no Brasil: a contribuição dos egressos de Coimbra. Curitiba: Juruá, 2001, p. 120-121.

20 Um retrato fidedigno do cenário das ideias no Brasil é feito por J. R. de L. Lopes, quando assevera que "nas monarquias, a vontade do soberano vai sendo matizada. $\mathrm{O}$ caso do Brasil é significativo. Trata-se de uma monarquia constitucional em que está aceita a ideia de que as leis são, afinal de contas, produto da vontade da maioria representada na Assembleia Geral do Império (Câmara e Senado). Trata-se, porém, de uma monarquia com instituições conservadoras (Poder Moderador, Senado vitalício, Conselho de Estado, eleições indiretas, Igreja de Estado etc.). Uma interpretação que procedesse diretamente do jusnaturalismo ‘antropológico’ de Grócio, Hobbes ou Pufendorf poderia levar a interpretações utilitaristas da ordem jurídica e, em última instância, minar a estabilidade de algumas instituições nacionais, como a escravidão. Os autores brasileiros do século XIX voltam-se então para o ecletismo: uma mistura de liberalismo fundado em algumas premissas jusnaturalistas - como a da igualdade de todos os homens - combinada com elementos organicistas, capazes de submeter a desordem dos interesses individuais a uma ordem 'providencial' e 'racional”. LOPES, José Reinaldo de Lima. As palavras e a lei: direito, ordem e justiça na história do pensamento jurídico moderno. São Paulo: Editora 34 - Edesp, 2004, p. 126. 
dentro desse plano de elaboração legislativa.

Contudo, no período posterior, de 1870 a 1890, o ideário em pauta é o de renovação, tendo por pano de fundo a questão republicana. Nesse contexto, surge o naturalismo, fruto dos debates sobre o evolucionismo e as conquistas científicas, em que despontam figuras na área jurídica que representaram a ruptura com o passado, como no caso de Tobias Barreto e de Sílvio Romero. $\mathrm{O}$ pensamento de tais autores formou uma nova mentalidade no país ${ }^{21}$, a "Escola de Recife", que viria a dominar o discurso jurídico desse período e que alcançaria o auge durante a elaboração do Projeto de Código de Bevilaqua. De fato, o seu predomínio favoreceu posteriormente, já no início do século $\mathrm{XX}$, o surgimento do positivismo comteano, de autores como Pedro Lessa, que combate a doutrina que representa a continuação de uma noção tradicional do Direito, como a doutrina escolástica de Soriano de Sousa, que era das décadas de 1860 a 1890.

Ante esse cenário, pode-se apontar que Teixeira de Freitas compreendeu seu papel dentro desse contexto de ideias, já que, a partir do momento em que teve a responsabilidade de ordenar a prática jurídica civil com a Consolidação, fazendo, logo depois, o projeto de Código, percebeu o peso da função que recebera. Por isso, deveria restabelecer a concepção da tradição jurídica luso-brasileira com uma atualização necessária, isto é, a construção de uma legislação nacional apta para a época, analogamente dentro do espírito que Savigny ${ }^{22}$ em seu contexto queria colocar na política legislativa

21 A respeito da Escola de Recife e a sua correspondência de ideias com o projeto de Código Civil feito no ano de 1899 por C. Bevilaqua, que se converteria no primeiro Código Civil do país em 1916, argumentava C. do Couto e Silva que "a influência do Direito germânico cresce no Direito brasileiro com a orientação que lhe deu Tobias Barreto, conhecida sob a denominação de Escola de Recife. O Código Civil recebe em grande medida estas novas ideias, pois seu autor era um dos corifeus dessa orientação cultural”. DO COUTO E SILVA, Clóvis Veríssimo. O direito civil brasileiro em perspectiva histórica e visão de futuro. Cit., p. 18.

22 A força das ideias novas do discurso iluminista eram sentidas em todo o mundo ocidental no século XIX; isso explica tal visão de Savigny, como assevera A. Dal Ri Jr., "é nesse contexto, e na angústia dessas reflexões sobre o destino da cultura jurídica germânica, que Savigny busca perspectivas novas para o Direito da sua gente. Tenta, mais do que qualquer coisa, evitar a implantação cultural de modelos jurídicos e políticos externos, não condizentes com as tradições historicamente consolidadas pelo seu povo”. DAL RI JR., Arno. O humanismo jurídico segundo Friedrich K. von Savigny. In: DAL RI JR., A. \& PAVIANI, J. O humanismo latino no Brasil de hoje. Belo Horizonte: PUC Minas, 2001, p. 150-167, esp. p. 153. 
de seu período. Esse é o sentido que norteia a sua compreensão a respeito da codificação.

Por outro lado, soube posicionarse numa circunstância adversa ${ }^{23}$, em que o ponto de vista político (a luta republicana e abolicionista) era o que estava em voga, desprestigiando a verdadeira interpretação jurídica dos fatos em prol do domínio do discurso de forte conotação política. Vale lembrar que Teixeira de Freitas nunca defendeu o predomínio do político sobre o jurídico, fato esse que era típico no pensamento dos autores da época, ainda mais ante as mazelas do Império e as respostas exaltadas em razão da escravidão, mas sempre considerou que todas as modificações necessárias para atender às necessidades da época deveriam ser feitas no plano da legislação, o que garantia a segurança jurídica na sua interpretação para efeitos de aplicação nas relações jurídicas.

\section{A presença do realismo jurídico em Teixeira de Freitas}

Partindo do que se apresentou anteriormente, pode-se dizer que o ponto de vista externo, de fazer a reconstituição das fontes de trabalho de Teixeira de Freitas, confirma a continuidade do pensamento filosófico clássico, de origem nas Escolas jurídicas medievais, no contexto do autor. A reconstituição dessa linha se dá desde a tradição jurídica luso-brasileira, que se consolida nas Ordenações, passando pela reordenação pombalina, que nutre as suas raízes no Iluminismo católico, para chegar até o momento das suas obras. $\mathrm{O}$ que se percebe é que, na época de Teixeira de Freitas, a visão eclética filosófica que predomina principalmente no $2^{\circ}$ Império favoreceu a manutenção de postulados tradicionais do Direito, de modo especial na prática forense.

Entretanto, essa presença da filosofia clássica no pensamento de Teixeira de Freitas somente se observa na perspectiva interna, ou seja, tentando compreender a visão que tinha esse jurisconsulto sobre o fenômeno jurídico. Aqui radica a singularidade de Teixeira de Freitas, a peculiaridade de buscar atualizar o ideário jusnaturalista clássico concomitante à incumbência de elaborar uma codi-

23 Nesse sentido, segundo transcrição de S. Meira, seria possível recordar que o compilador brasileiro afirma, numa polêmica com C. A. Soares em 1857 no "Instituto dos Advogados do Brasil” a respeito da escravidão, que “em questões abstratas de jurisprudência, não posso compreender que se desenvolvam paixões; não sei também que fruto se possa colher dos assaltos de uma primeira ideia, e arrebatamentos do entusiasmo, em matéria de pura observação e raciocínio”. MEIRA, S. A polêmica de Teixeira de Freitas e Caetano Alberto Soares. Arquivos do Ministério da Justiça, ano 41, n. 171, jan.-mar. 1988, p. 41-77, esp. p. 45. 
ficação tipicamente moderna. Entretanto, não se quer aqui afirmar uma incongruência na mente de Teixeira de Freitas: de fato, não parece que tal autor buscava simplesmente conjugar princípios jurídicos radicados na experiência jurídica romano-medieval e na técnica moderna. Na verdade, há uma essência material e formal que advém do Direito romano e da legislação medieval que, por sua vez, deve ser apropriada e processada para sua época. Essa caracterização pode ser visualizada em dois tópicos, a saber: (3.1) o método utilizado pelo autor e (3.2) a aplicação da visão realista em seus trabalhos.

\subsection{A metodologia do jurisconsulto}

No que se refere ao método empregado por Teixeira de Freitas, é possível indicar alguns pontos em que o jurista brasileiro mostra sua compreensão a respeito dos fenômenos do Direito segundo os padrões defendidos pela tradição jusnaturalista clássica.

De início, pode-se fazer referência à utilização do Direito romano como paradigma para os trabalhos de codificação ${ }^{24}$. Nesse aspecto, a preocupação de Teixeira de Freitas foi a de reconstruir uma linguagem jurídica que representasse a realidade dos fatos, de onde se depreende a razão pela qual o Direito romano se colocaria como exemplo para promover a ordenação da legislação civil no Brasil. Contudo, cumpre salientar que sua admiração pela concepção jurídica romana não resultou numa postura de rejeição da compreensão moderna de necessidade de uma sistematização da legislação nem tampouco na idolatria anacrônica da citada visão romana em todos seus conceitos e sentidos. Pelo contrário, o jurista reconhecia a necessidade de uma adequação à sua época, sempre partindo das origens romanas e lusitanas; por outro lado, soube também diferenciar as noções ainda válidas do antigo ordenamento romano e aquilo que não era mais aplicável em sua realidade.

Além desse ponto de vista material, era também característico o enfoque formal, em que o jurisconsulto buscou estipular um critério lógico de classificação da matéria jurídica, de acordo com cada trabalho legislativo que deveria empreender. Desse modo,

24 Nesse sentido, afirma E. de Moraes Filho que o Direito romano serviria de paradigma durante a construção do sistema jurídico de Teixeira de Freitas, atuando como um critério seguro em que o autor utilizava a cada momento na elaboração e aplicação de seu sistema. Contudo, não era um modelo incontestável e imutável, pois o famoso jurista opinava que o Direito romano teria também alguns problemas. DE MORAES FILHO, Evaristo. Teixeira de Freitas, a busca da perfeição e a dogmática jurídica. $R e-$ vista Forense, ano 81, jul.-set. 1985, vol. 291, p. 1-22, esp. p. 10-11. 
ao compilar a legislação civil nacional na Consolidação, Teixeira de Freitas referia à necessidade de ter um critério mais universal para ordenar toda a matéria civil, o que encontraria na distinção entre direitos pessoais e direitos reais ${ }^{25}$. Por sua vez, ao elaborar o Esboço, tratando-se de um projeto de Código Civil, o autor acrescentou mais um critério, ainda mais universal, que foi a distinção entre direitos absolutos e direitos relativos. Nessa busca se visualiza um vínculo com a tradição jusnaturalista clássica, quando o jurisconsulto deixa claro que os seus critérios são definidos com base na percepção da natureza das instituições jurídicas na realidade, ou seja, nos fatos e nas relações do Direito.

Por fim, é possível ainda recordar, dentro deste enfoque formal, a busca da "unidade superior" na matéria, justamente o corolário desse ponto de vista formal. Destarte, Teixeira de Freitas percebe que a definição dos critérios de ordenação da matéria deve resultar na possibilidade de fazer conexões entre as instituições jurídicas com o objetivo de construir um sistema jurídico que busque a perfeição técnica.

\subsection{A aplicação do método realista na obra de Teixeira de Freitas}

O segundo aspecto que corrobora a visão clássica no ideário de Teixeira de Freitas é a aplicação dos critérios do Realismo jurídico nas suas obras. Também nesse caso, indicam-se algumas características que ressaltam essa noção.

Assim, o primeiro sinal da aplicação dos postulados clássicos seria a compreensão de caráter concreto que exibe em suas obras, visualizável desde sua atuação advocatícia, que era muito reconhecida na época. É possível ainda apontar tópicos específicos, que confirmam tal concepção, dentre os quais pelo menos um é característico - a atenção dada por Teixeira de Freitas para as relações econômicas na sociedade brasileira daquela época, como de fato haveria de manifestar quando da ordenação da matéria civil para efeitos da Consolidação.

25 De fato, diz Teixeira de Freitas sobre tal divisão que "ella estava latente em todos os Codigos e Legislações, manifestava-se variadamente por expressões dubias, achava-se, e persistirá eternamente, no pensamento analytico e synthetico do Direito, actuava por effeitos sensiveis e praticos na scena judiciaria, reapparecia na scena economica sob a face de valor, e ultimamente veio ostentar toda a sua importancia nas novas idéas sobre o regimen hypothecario moderno. Nada mais fizemos do que tirar partido dessa capital distincção, tão exacta para o espirito, como apreciavel na vida real, colhendo della mais uma applicação, que não era para desprezar”. Nova apostilla á censura do Senhor Alberto de Moraes Carvalho sobre o Projecto do Codigo civil portuguez. Cit., p. 10-11. 
Porém, não se restringe somente a isso a influência da metodologia realista no autor. Pode-se apontar ainda a defesa da razão prática, a razoabilidade. Isso se ratifica em sua atenção para com a realidade nacional no momento em que regula os fatos em suas obras. Aqui justamente se percebe que Teixeira de Freitas opta pelo realismo clássico, também no intuito de evitar o idealismo com a sua mera aplicação de postulados conceituais de origem filosófica para definir a natureza das instituições e regras do Direito, prática essa que foi tão comum entre os autores do período e que segue em voga até os dias atuais.

Sinteticamente, nessa perspectiva, pode-se anotar que o jurista respeitou os valores básicos da cultura do país. Por essa razão, tinha posições fortes, o que infelizmente explica o seu isolamento no final de sua vida. Entre tais posições estava o seu rechaço à escravidão ainda vigente na época, porém não dentro de uma cartilha de índole republicanista, comum no período. Na verdade, Teixeira de Freitas entendia que seriam necessárias modificações legislativas de peso para uma verdadeira mudança, o almejado fim da escravidão. Dizia isso porque sabia que o tema da condição do escravo se convertera simplesmente em mais um tópico dos debates entre os políticos da época, tornando-se com isso em mote para ações de movimentos políticos que representavam defesas de interesses, sem manifestar preocupação pelo bem comum. Ao defender uma via de definição jurídica e legal, o que era diferente do que era estipulado no debate político monarquista-republicano nesse tema, o resultado foi que ficou estigmatizado como se fosse um escravocrata e, ao mesmo tempo, como um crítico da legislação libertária do final do Império e da política do próprio imperador. Infelizmente, ao estigmatizá-lo seus contemporâneos não quiseram lembrar que Teixeira de Freitas havia dado várias cartas de alforria a escravos. Como se vê, sua solução de cobrar o rigor na legislação não era bem-vista numa época de debates que beiravam ao embate ideológico e demagógico.

Nesse mesmo caminho, quando estabelece uma definição da condição de pessoa no Esboço, o autor defende o nascituro, enquadrando-o como "pessoa por nascer" ${ }^{26}$ no texto do projeto de Código. Indubitavelmente, tal posição representava para o autor que esse ente no ventre materno possuía a

26 Com efeito, estabeleceu Teixeira de Freitas no art. 53 do Esboço que "são pessoas por nascêr as que, não sendo ainda nascidas, achão-se porem já concebidas no ventre materno". TEIXEIRA DE FREITAS, Augusto. Codigo civil - Esboço. fasc. I. Rio de Janeiro, Typographia Universal de Laemmert, 1860, p. 59. 
personalidade jurídica como qualquer outro ser humano, de onde resultavam na sua visão inúmeros direitos civis e de personalidade para o nascituro.

\section{CONCLUSÃO}

Para concluir essa investigação, depois da exposição de argumentos é o momento de apresentar algumas conclusões a respeito da relação entre Teixeira de Freitas e o realismo clássico. Em primeiro lugar, percebe-se em suas obras uma visão profunda da realidade, já que tem sempre em conta a compreensão do jurista romano na interpretação das relações jurídicas. Com isso, nota-se que não atuou como grande parte dos autores de mentalidade moderna, os quais, por sua vez, ao elaborarem sistemas jurídicos doutrinais ou legislativos deduziram tudo de alguns postulados teoréticos.

Ademais, defende a verdade evidente nos fenômenos baseado na noção de "natureza das coisas", dentro dos limites da própria tradição lusobrasileira. Nesse sentido, em suas obras não é comum encontrar citações de filósofos do pensamento clássico, mas isso não é propriamente um obstáculo para que seja enquadrado como jusnaturalista, isso porque foi um verdadeiro defensor do Realismo jurídico clássico usando a linguagem de sua época e tendo a percepção correta dos fatos e das relações jurídicas, como se pode vislumbrar nas suas obras legislativas.

De outra banda, o conjunto de sua obra confirma que houve inserção dos postulados do Realismo jurídico na cultura brasileira, em especial no Direito civil. A raiz disso estava na história, pois, desde a prática do "bartolismo” no início da Modernidade em Portugal e depois, em certo sentido, com o "praxismo" lusitano da época pombalina, valorizou-se uma concepção prática do Direito que tinha em conta o concreto das relações. Vale lembrar aqui que houve uma forte influência do método escolástico medieval na prática "bartolista” em vista da formação dos juristas portugueses desde a Escola dos comentadores. No que tange ao modelo do "Usus modernus”, Pombal buscou uma profunda modificação da experiência jurídica portuguesa, abrindo caminho para consolidar uma influência da Escola de Direito Natural racional em Portugal. No entanto, num primeiro momento, a modificação ficou mais no plano do uso do direito subsidiário da legislação “moderna” da época que estava sendo produzida nas outras nações, mas não chegou a alterar a dinâmica do uso das Ordenações, com sua visão vincada na prática antiga; essa experiência se dava em Portugal, e por isso também no Brasil, até ao menos a consolidação da codificação do século XIX, quando então o movimento das ideias era totalmente diverso da postura an- 
tiga e tradicional. Quando ocorre a quebra com a tradição, consolida-se o discurso idealista, bastando lembrar para tanto figuras daquela época, como o filósofo de moda em meados desse século XIX em Portugal, Vicente F. Neto Paiva, que representa bem o novo pensamento português.

Tendo por base a visão de Teixeira de Freitas a respeito do Direito, a questão central da indagação filosófica sobre a técnica jurídica fica delineada a partir da percepção de sua função na concreção que ocorreu no processo codificatório. Explicando em outros termos: tal processo de legislação deveria configurar-se como um reflexo das instituições jurídicas, pois a construção do sistema jurídico em cada área deve possuir um fundamento, que são as instituições como manifestação da realidade concreta. Assim, aceitando-se tal compreensão da técnica jurídica, fica patente que o pensamento contemporâneo, correntemente chamado de pós-positivismo, pode resultar numa rejeição da formalidade da técnica jurídica em prol da arbitrariedade do detentor do poder ou do mero consenso social, pois nega veementemente um fundamento na realidade aos moldes clássicos.

Não se pode esquecer ainda que Teixeira de Freitas consegue mostrar claramente o critério correto para a construção da legislação. Isso ocorre porque tem bem claro qual é o limite da tarefa legislativa, no seu caso particular, quando elabora a compilação de leis civis ou o projeto de Código Civil. Com tal percepção, evita chegar a uma visão extremada, que é própria do cientificismo ainda vigente em meados do século em que viveu, como é possível observar no primeiro R. von Jhering, que, no seu Espírito do Direito romano, defende uma construção jurídica laboratorial. Além do mais, Teixeira de Freitas também consegue evitar a implantação de um modelo filosófico iluminista na ciência jurídica dos Oitocentos, o que, aparentemente e segundo a opinião de vários autores, foi obra de G. F. Puchta, reconhecido discípulo de Savigny, que teria iniciado a Jurisprudência dos conceitos.

Em síntese, pode-se afirmar que Teixeira de Freitas estabelece padrões para o rigor técnico de construção do sistema jurídico civil, colocando as instituições jurídicas civis no seu devido lugar e, ao mesmo tempo, mantendo um vínculo com a realidade dos fenômenos jurídicos, que se apresenta nos fatos e nas relações jurídicas, o que é próprio do pensamento e do método do Realismo clássico. 